\title{
Recorregut de recerca geològica i mineralògica per la comarca del Pallars Jussà (per la Vall Fosca): des d'Espui, al Coll de Triador, I'Estany Gento, I’Estany Tort i a Colomines
}

Josep Maria Mata-Perelló

Joaquim Sanz Balagué

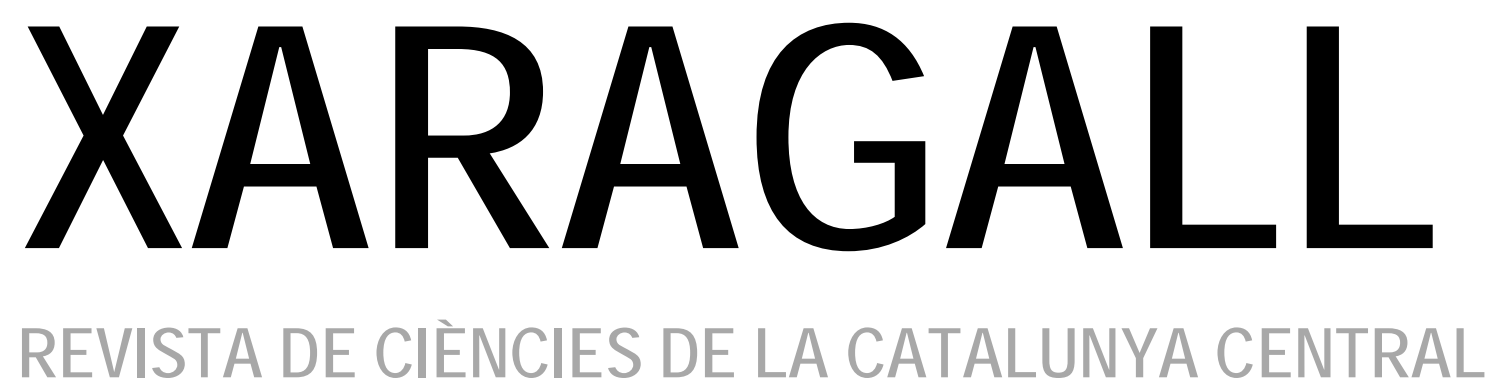

n. 8

AGOST 2015

Com citar l'article: Mata-Perelló, JM.; Sanz Balaguer, J. Recorregut de recerca geològica i mineralògica per la comarca del Pallars Jussà (per la Vall Fosca): des d’Espui, al Coll de Triador, I'Estany Gento, I'Estany Tort i a Colomines. A: XARAGALL. Revista de Ciències de la Catalunya Central. 2015. (n.8). ISSN 2013-4479 DL: B.21483-2009. DOI 


\title{
RECORREGUT DE RECERCA GEOLÒGICA I MINERALÒGICA PER LA COMARCA DEL PALLARS JUSSÀ (PER LA VALL FOSCA): DES D’ESPUI, AL COLL DE TRIADOR, L'ESTANY GENTO, L'ESTANY TORT I A COLOMINES
}

\author{
Josep Maria Mata-Perelló \\ Museu de geologia Valentí Masachs, Escola Politècnica Superior d'Enginyeria de Manresa \\ (EPSEM), Universitat Politècnica de Catalunya · BarcelonaTech (UPC), 08272 Manresa, Spain
}

\section{Joaquim Sanz Balagué}

Departament d'Enginyeria Minera i Recursos Naturals (EMRN), Escola Politècnica Superior d'Enginyeria de Manresa (EPSEM), Universitat Politècnica de Catalunya . BarcelonaTech (UPC), 08272 Manresa, Spain

Paraules clau: Sistema Pirinenc, Materials paleozoics, Materials mesozoics, Patrimoni miner

\section{Resum}

Itinerari realitzat el 7 d'agost de 2014. En aquesta ocasió, la totalitat del recorregut de l'itinerari es desenvoluparà per una sola unitat geològica: concretament pel Sistema Pirinenc, i més exactament per la zona de contacte entre la Unitat de les Nogueres i la Zona Axial Pirinenca, situada al nord de l'anterior. D'aquesta manera, el recorregut s'iniciarà a la població d'Espui (del terme de la Torre de Cabdella), situada a la Unitat de les Nogueres.

Així, a partir d'aquí l'itinerari transitarà per aquesta unitat acabada d'esmentar, anant cap a I'Estany Gento. Més amunt, en arribar-hi, es trobarà el contacte amb la Zona Axial Pirinenca, que ja no s'abandonarà en tota la resta del recorregut.

Així, inicialment, s'aniran trobant afloraments dels materials paleozoics del Silurià i del Devonià. Més endavant, en arribar a la Zona Axial, es trobaran granits i granodiorites carboníferes., així com afloraments paleozoics de I'Ordovicià, Silurià i Devonià, fonamentalment.

Per altra banda, aquest itinerari es desenvoluparà dintre de la comarca del Pallars Jussà (per la qual es transitarà entre la població d’Espui i la fi del recorregut, per les immediacions de I'Estany de Colomines). Així, tot el recorregut de l'itinerari s'efectuarà per la part més alta de la Vall Fosca, una subcomarca del Pallars Jussà. Aquesta subcomarca es troba situada íntegrament dintre de la conca fluvial del Noguera de Flamisell, afluent del Noguera Pallaresa a la Pobla de Segur. 


\section{Objectius fonamentals}

Es centraran en els aspectes geològics, geomorfològics i mineralògics que apuntarem a continuació:

1. Observació dels materials que constitueixen la Unitat de les Nogueres, que anirem trobant entre Espui i les immediacions de l’Estany Gento. Aquests materials pertanyen, en aquest tram, exclusivament al paleozoic (repartint-se entre el Carbonífer, el Devonià i el Silurià). Així, trobarem afloraments del Carbonífer (amb trams d'esquistos negres, fonamentalment), del Devonià (amb trams de calcàries) i del Silurià (amb pissarres negres, molt grafitoses i piritoses)

2. Observació dels materials que constitueixen la Zona Axial Pirinenca, que anirem trobant entre les immediacions de l’Estany Gento i la fi del recorregut. Aquests materials pertanyen, exclusivament al paleozoic (repartint-se entre el Carbonífer, el Devonià, el Silurià i l'Ordovicià). Així, trobarem afloraments de l'Ordovicià (amb trams d'esquistos, fonamentalment), del Silurià (amb pissarres negres, molt grafitoses i piritoses), del Devonià (amb trams de calcàries ) i del Carbonífer (amb granits i granodiorites).

3. Observació de les relacions existents entre les dues subunitats pirinenques acabades d'esmentar.

4. Observació de les diferents mineralitzacions que anirem trobant al llarg del recorregut, si es dona el cas.

5. Observació al llarg del recorregut de l'itinerari de les antigues explotacions situades al llarg del recorregut.

6. Observació de l'impacte produït sobre el Medi Natural, tant de la mineria com a conseqüència de les obres efectuades per la zona.

7. Observació dels indrets relacionats amb el patrimoni geològic, que es vagi trobant al llarg del recorregut.

8. Observació dels indrets relacionats amb el patrimoni miner, que es vagi trobant al llarg del recorregut. 


\section{Antecedents}

Pel que fa al recorregut del present itinerari, existeix alguns antecedents nostres. Es tracta de MATA - PERELLÓ (2013a i 2013b). Tret d'aquests, cal fer esment d'un important treball (MARTINEZ 2013), amb un recull d'itineraris geològics pel Parc Nacional d'Aigües Tortes i de Sant Maurici.

Pel que fa a la descripció de les mineralitzacions, cal parlar d'un altre treball, també nostre; en concret de MATA-PERELLÓ (1991). Aquest treball es relatiu a les mineralitzacions catalanes en general, amb un capítol dedicat a la Noguera. També cal fer esment de MATA-PERELLÓ i SANZ (1993), dedicat al reconeixement dels minerals.

I pel que fa a l'estructura geològica de la zona per la qual discorre l'itinerari, farem esment de dos treballs, molt interessants, de caràcter generalista. En concret, ens estem referint als següents: GUIMERÀ et altri (1982). i també a RIBA et altri (1976). Tots dos treballs es refereixen a la geologia dels Països Catalans, i conseqüentment de Catalunya. Per d'altra banda, també cal fer esment del treball de ROSELL (1970); així com de l'IGME (1994).

Tots aquests treballs referenciats, i d'altres, figuren esmentats per ordre alfabètic a l'apartat dedicat a la BIBLIOGRAFIA.

\section{Recorregut de l'itinerari}

El recorregut de l'itinerari discorrerà per una comarca de la Regió de Tremp - la Seu d'Urgell; concretament per la del Pallars Jussà i dintre d'aquesta per la Vall Fosca, en els seu tram superior. Així, el recorregut s'iniciarà a la població d'Espui, situada a la Vall del Flamisell, situada sobre la carretera local $L-503$. A partir d'aquesta població, ens caldrà pujar cap a les immediacions del Coll de Triadors, tot seguint una pista. Cal dir que aquest recorregut l'efectuarem dintre del Mantell de la Zona de les Nogueres.

Després. es caldrà continuar a peu, tot seguint l'antic recorregut del ferrocarril que s'adreça fins a I'Estany Gento. En aquest recorregut, haurem transitat pel Mantell de les Nogueres. Posteriorment, poc abans d'arribar a I'Estany Gento, haurem entrat a la Zona Axial Pirinenca, que ja no abandonarem.

Des d'aquí, el recorregut es dirigirà cap a l'Estany Tort i cap al Refugi de Colomina, per on finalitzarà el recorregut de l'itinerari. Al llarg de tot aquest recorregut, $s^{\prime}$ aniran fent diverses aturades, sense abandonar la Zona Axial Pirinenca. 


\section{Advertiments previs}

Com en altres recorreguts de RECERCA GEOLÒGICA I MINERALÒGICA... si es disposa del temps suficient, poden efectuar-se passant per totes les parades i filloles. En cas contrari, recomanem prescindir de les anomenades PARADES - CONDICIONALS.

També cal tenir en conte que una part del recorregut de l'itinerari, es realitzarà per camins de terra, per la qual cosa caldrà prendre les degudes precaucions. Per d'altra banda, una bona part del recorregut es realitzarà a peu, tot anant des del Coll de Triador, fins a I'Estany Gento, I'Estany Tort i fins al Refugi de Colomines

Cal tenir, com sempre, una cura molt especial de respecte a la natura, al llarg de tot el recorregut de l'itinerari, i també fora d'ell.

\section{Descripció de l'itinerari}

En aquest recorregut hem situat, com ja és habitual en tots els itineraris, una sèrie d'ESTACIONS o de PARADES, que anirem veient a continuació. En cada cas, els hi donarem una denominació que podrà correspondre a algun paratge proper. També indicarem el terme municipal i la comarca on es troba.

Per altra banda, en cada una de les parades, indicarem entre parèntesi el número del "Mapa Topográfico", a escala 1:50.000, on es troba situada la parada considerada. En aquesta ocasió serà algun dels següents: 181 (o d'Esterri d'Áneu) i 214 (o de Sort).

Així doncs, la relació ordenada de les parades que composen aquest recorregut, és la següent.

\subsection{Parada 1. INICI DEL CAMÍ D’ESPUI CAP EL COLL DE TRIADOR, (Espui, terme municipal de la Torre de Cabdella, la Vall Fosca, comarca del Pallars Jussà). (Full 214).}

El recorregut d'aquest itinerari, el començarem a la població d’Espui, situada al bell mig de la vall, aigües amunt de la seva capital administrativa, la població de la Torre de Cabdella. Així, I'iniciarem el recorregut, al començament del camí - pista que es dirigeix cap a llevant, per tal d'arribar fins a les immediacions del Coll de Triador.

La població d'Espui, es troba situada dintre del Sistema Pirinenc, on es troba també tota la Vall Fosca. Tot i així, aquests sectors es troben situats dintre de a Unitat del Mantell de les Nogueres, però molt a prop de la Zona Axial Pirinenca. Així, per arreu, es veuen afloraments dels materials paleozoics del Devonià.

Efectivament, per aquests indrets predominen els terrenys eminentment carbonatats del Devonià. Es fàcil veure trams del Devonià Mig (amb calcàries de la Formació Manyanet $\mathrm{i}$ pissarres de la Formació Vilaller); i també trams més propers del Devonià Inferior (amb pissarres i calcaries de la Formació Basibé i amb pissarres i calcaries de la Formació Rueda). Tot i així, molt sovint, aquests materials es troben recoberts per terrenys neògens, del Pleistocè i de l'Holocè, d'origen glacial i fluvial, segons els indrets.

Des d'aquest indret, prop del pont sobre el Noguera de Flamisell, es pot veure la morfologia glacial d'aquesta vall. 


\subsection{Parada 2 - CONDICIONAL. IMMEDIACIONS DEL COLL DEL TRIADOR, (Espui i Llessui, termes municipal de la Torre de Cabdella i de Sort, comarques del Pallars Jussà i del Pallars Sobirà, respectivament). (Full 214).}

Des de la parada anterior, cal sortir de la població d'Espui, anant cap a l'Est, a través del camí - pista que es va dirigint cap el Coll de Triador, pujant sempre per la vorera occidental del Montsent de Pallars. En arribar a les immediacions del Coll de Triador, farem una nova aturada, després d'un recorregut proper als $10 \mathrm{Km}$, des de la parada anterior.

En aquest recorregut, sempre ascendent, haurem trobat afloraments dels diferents materials que formen part dels materials paleozoics del Mantell de les Nogueres, on ens trobem situats. Així, haurem vist afloraments dels materials paleozoics (primer del Devonià, i després del Silurià i de I'Ordovicià).

Tot i això, aquests materials es troben recoberts, molt sovint per terrenys detrítics cenozoics, neògens (del Pleistocè i de l'Holocè), d'origen generalment glacial o fluvial, segons els indrets. Així, sovint, haurem trobat afloraments de les morrenes glacials per tot arreu, procedents del glacial de la Vall Fosca.

\subsection{Parada 3. BARRANC DE CUIROLA, (Cabdella, terme municipal de la Torre de Cabdella, comarca del Pallars Jussà). (Full 214).}

Des de la parada anterior, cal continuar pel camí - pista que va conduint cap a Cambra d'Aigües. En arribar-hi, ens caldrà continuar a peu, tot seguint l'antic carrilet que anava cap a I'Estany Gento. A poc més de $1-1^{\prime} 5 \mathrm{Km}$, arribarem a les immediacions del Barranc de Cuirola, que baixa des del Montsent de Pallars. Aquí, podem fer una nova aturada, a uns 2'5 $\mathrm{Km}$ de la parada anterior, aproximadament.

En aquest recorregut, hem continuat trobant els materials esmentats a l'atirada anterior, fonamentalment els nivells pissarrencs del Silurià i els esquistosos de l'Ordovicià. Aquests darrers els trobem a l'indret de la present aturada. Tot i així, en bona part del recorregut, hem anant trobant afloraments dels terrenys pissarrencs del Silurià.

Per altra banda, per sobre nostre, es fan clarament palesos els afloraments dels materials carbonatats del Devonià. Aquests formen part dels relleus del Montsent de Pallars, situats a I’Est del vial que anem seguint.

També hem trobat per arreu, afloraments dels materials detrítics d'origen glacial, molt heteromètrics, formen part de les antigues morrenes. Aquests materials del Pleistocè i de l'Holocè, cobreixen a tots els anteriors.

Des d'aquest indret, mirant cap a ponent, es pot veure la Vall de Filià. Es tracta d'una interessant vall glacial penjada, afluent de I'arteria glacial principal, que passava per I'actual Vall Fosca. Efectivament, cal considerar que per aquesta vall lateral, situada per sobre d'Espui, corria un glacial, tributari del que seguia la Vall Fosca. (fotografies 1 i 2). 


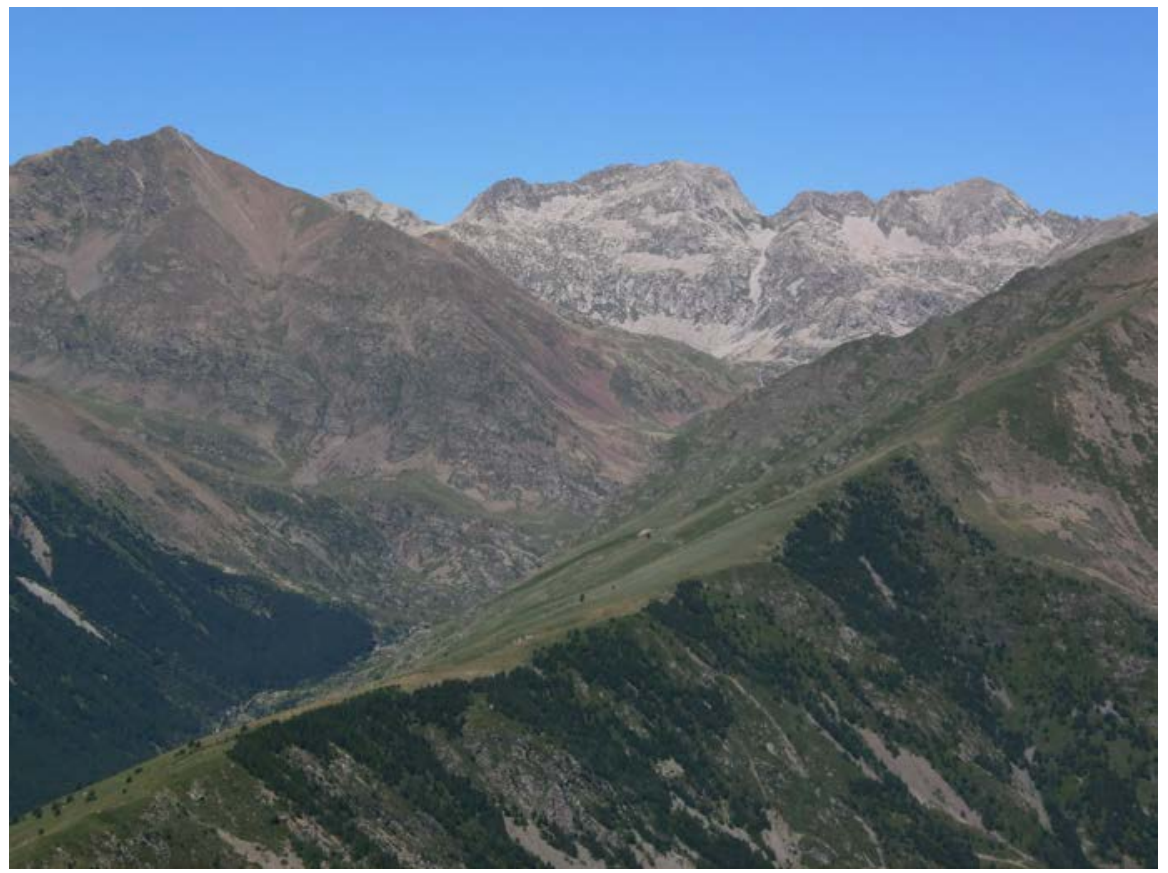

Fotografia 1. Un aspecte de la Vall de Filià. Agost 2013

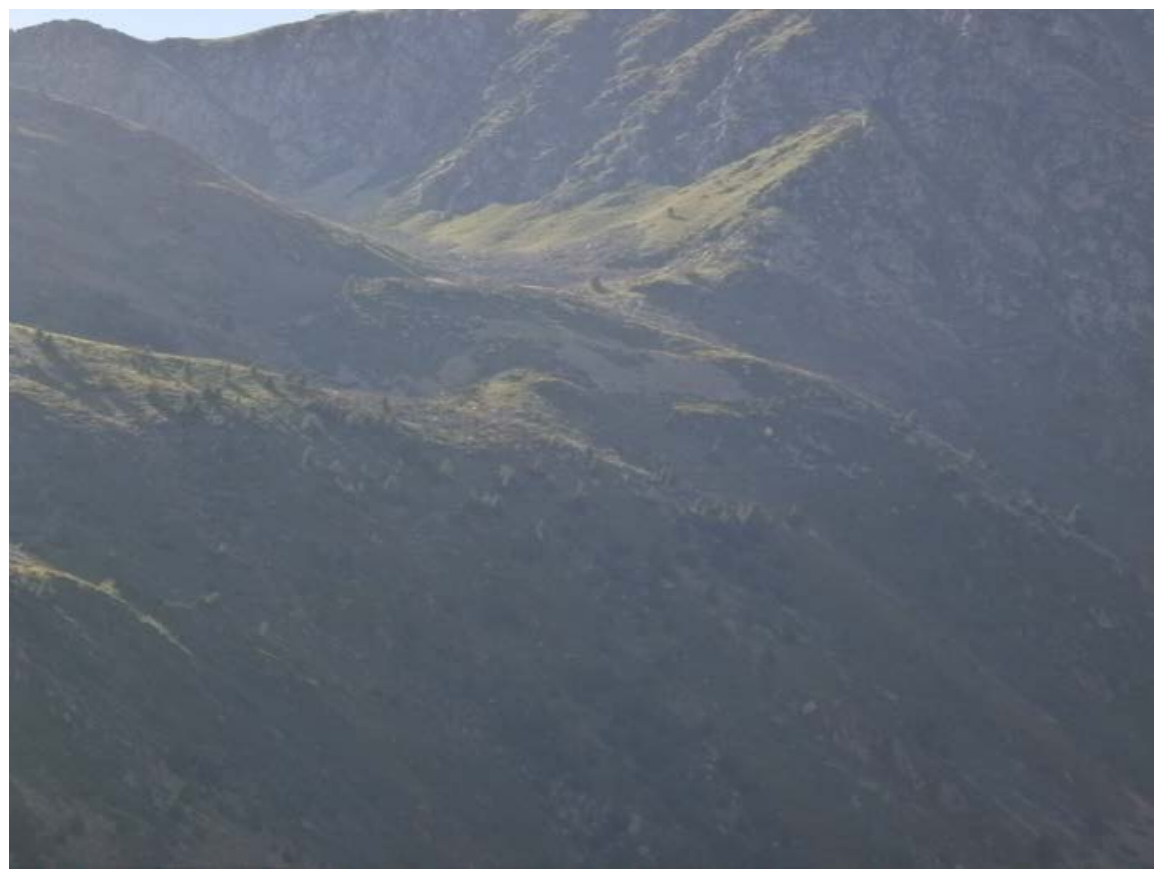

Fotografia 2. Un altre aspecte de la Vall de Filià. Juliol 2013 Vall Fosca): des d'Espui, al Coll de Triador, I'Estany Gento, I'Estany Tort i a Colomines 


\subsection{Parada 4. BARRANC DE VALLDOMARS, IMMEDIACIONS DE LA PALA DE LA RODA, (Cabdella, terme municipal de la Torre de Cabdella, comarca del Pallars Jussà). (Full 181).}

Després de realitzar la parada anterior, cal continuar per la plataforma de l'antic ferrocarril, que es va apropant cap a l'Estany Gento. A poc més de $1^{\prime} 5-2 \mathrm{Km}$ de la parada anterior, per les immediacions de la Pala de la Roda, després d'haver saturat el Barranc de Valldomars, podem fer una nova aturada.

En aquest tram, el camí va seguint un suau ascens, sempre per la vessant occidental del impressionant Monsent de Pallars, que queda a la nostra dreta. Mentre, a la nostra esquerra queda molt palesa la Vall Fosca.

En aquest recorregut, molt sovint haurem trobat afloraments dels materials carbonatats del Devonià (tot formant par de I'Encavalcament del Montsent), aquests nivells carbonatats sovint es troben fracturats.

Per altra banda, tanmateix, haurem trobat afloraments dels nivells pissarrencs del Silurià, de tonalitats molt fosques, sovint negres. Cal dir que aquests materials es troben generalment força replegats.

Des de l'indret de la present aturada, es pot fer una bona observació de la Vall Fosc, observant-se per arreu el seu aspecte glacial, amb una vall en forma de "U". Efectivament, era ocupada per un glacial. Tanmateix, a dreta i a esquerra, es poden veure diferents valls penjades, corresponents a antics glacials tributaris (com el que hem esmentat a la parada anterior, la Vall de Filià). (fotografía 3).

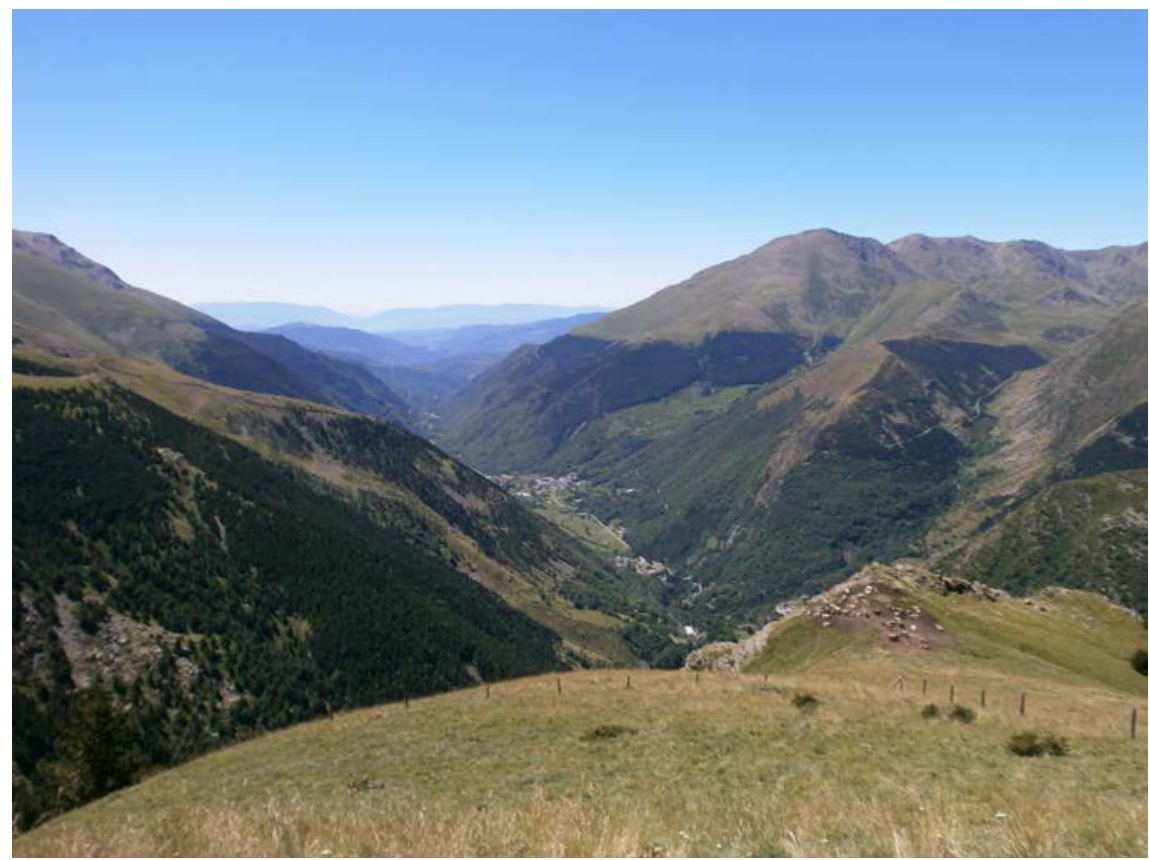

Fotografia 3. Un altre aspecte de la Vall Fosca, des de prop de la Pala de la Roda. Pot observar-se l’aspecte glacial de la vall principal i de les vals penjades. Agost 2013 
També es poden veure des d'aquest indret, els relleus de la Pala de Polvoròs i del Pic de I'Espada, situats a ponent d'on ara som. Aquest relleus marcaven la divisoria entre el glacial que baixava de Sallente i el que baixaba del Coll de Rus, constituint les actuals Vall Fosca i Ribera de Riguerna, que s'ajunten prop de Cabdella. (fotografia 4).

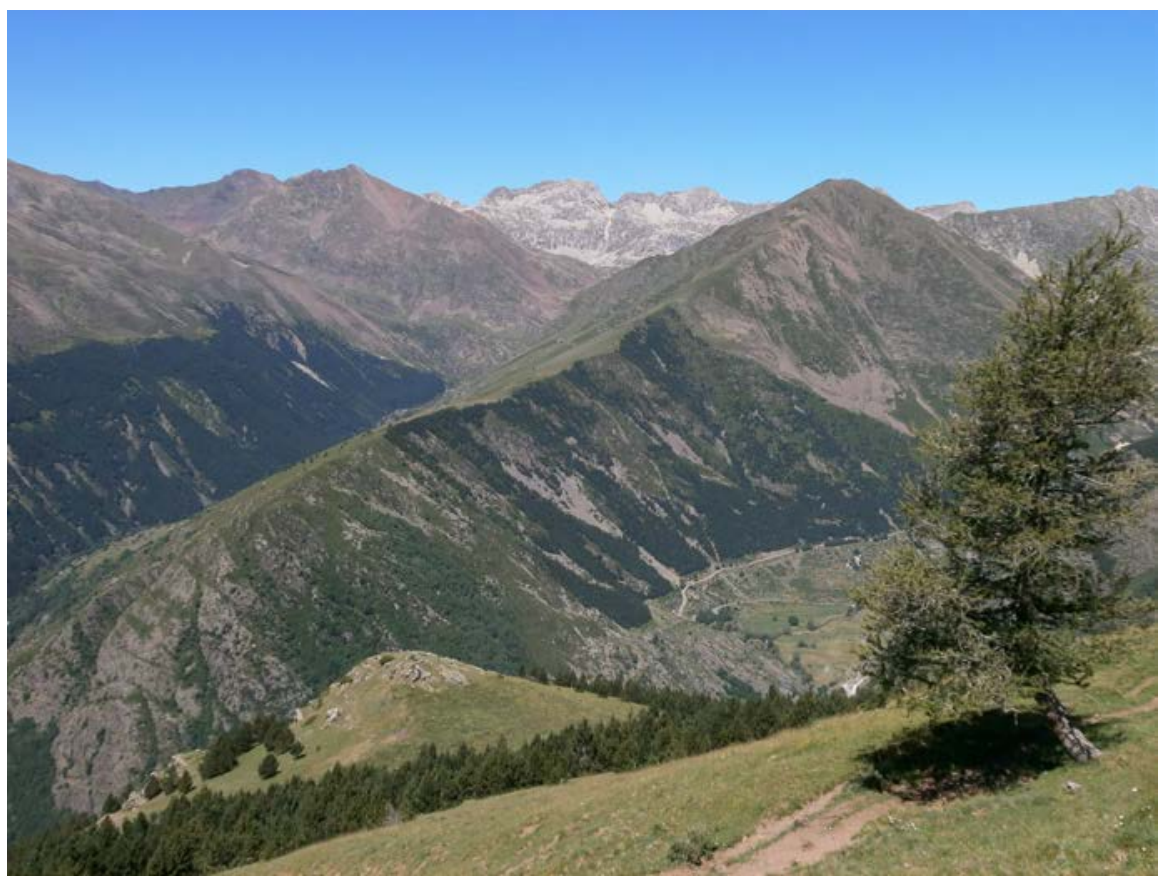

Fotografia 4. Un altre aspecte de la Pala de Polvoròs - Pic de I'Espada, separant la Vall Fosca i la Ribera de Riguerna. Era la divisoria que separava els dos glacials que baixaven per aquestes valls. Agost 2013.

\subsection{Parada 5. IMMEDIACIONS DEL CANAL DE PIGOLO, (Cabdella, terme municipal de la Torre de Cabdella, comarca del Pallars Jussà). (Full 181).}

Després de realitzar la parada anterior, cal continuar cap el Nord per la plataforma de l'antic ferrocarril, que es va apropant cap a l'Estany Gento. A poc més de 1'5 Km de la parada anterior, per les immediacions del Canal de Pigolo, prop d'un dels túnels d'aquesta antiga via ferroviària.

En aquest recorregut, hem anat trobant afloraments dels materials carbonatats del Devonià, dels quals ja hem fet esment a l'aturada anterior. Tot i que sovint, haurem vist també afloraments dels nivells pissarrencs del Silurià. Cal dir, que cada vegada més, estem entrant dintre de la Zona Axial Pirinenca. Per d'altra banda, també estem trobant afloraments del materials granítics i granodioritics carbonífers.

Tot i així, per arreu es fan palesos els recobriments dels materials anteriors, per part de depòsits neògens detrítics, generalment de procedència glacial, del Pleistocè i de l'Holocè. Aquests materials detrítics formen part de les morrenes glacials. 
En aquest tram, sovint hem vist com les freqüents esllavissades, han deformat les antigues vies del ferrocarril que anem seguint. Tanmateix, hem passant al costat d'una antiga esllavissada, molt patent.

Pel que fa al carrilet, cal dir que aquest es va utilitzar per a la construcció de les preses situades més amunt. En el seu recorregut, aquest carrilet passa de la Unitat del Mantell de les Nogueres (on es troba la Cambra d'Aigües, prop d'Espui, per on començat a caminar) a la Zona Axial Pirinenca per on ens trobem ara situats. Aquest carrilet va constituir al seu moment una important obra d'enginyeria. (fotografies 5 i 6 ).

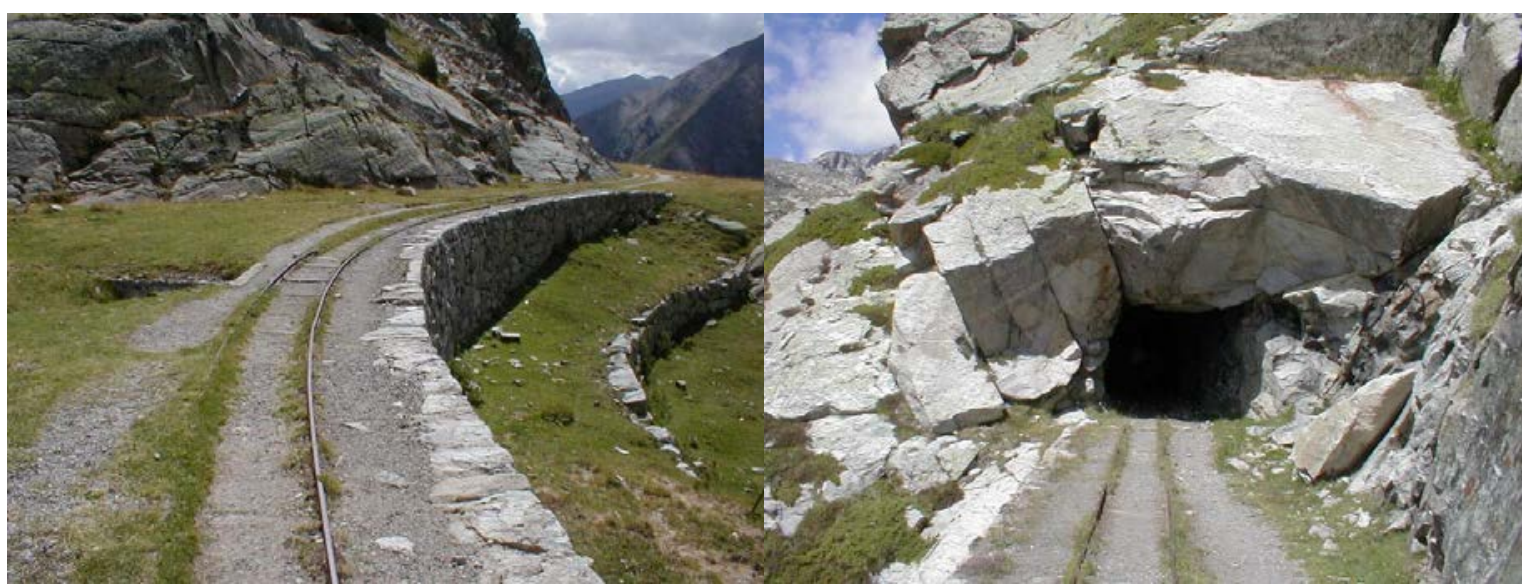

Fotografies 5 i 6 . Dos dels trams del carrilet de l'Estany Gento. Agost del 2013 Al segon, es pot apreciar un túnel obert entre afloraments de granodiorites.

Des d'aquest indret es pot fer una primera observació de Sallente. En en aquest lloc hi ha un interessant embassament, construït sobre la vall del riu Sallente. Aquest embassament forma part del sistema hidràulic Estany Gento - Sallente. En efecte, aquí es recullen les aigües de diversos llacs d'origen glacial, destinats a l'obtenció d'energia hidroelèctrica. Al mateix temps, aquest és un llac reversible, de forma que periòdicament les aigües es bombegen cap a I'Estant Gento, situat més amunt, ja dintre del Parc Nacional d'Aigües Tortes - Sant Maurici. Aquest sistema, és un dels més importants de tot els Pirineus i de la Península Ibèrica.

Des de la via que condueix cap a l'Estan Gento, es pot fer una primera observació de I'Embassament de Sallente. (fotografia 7). 


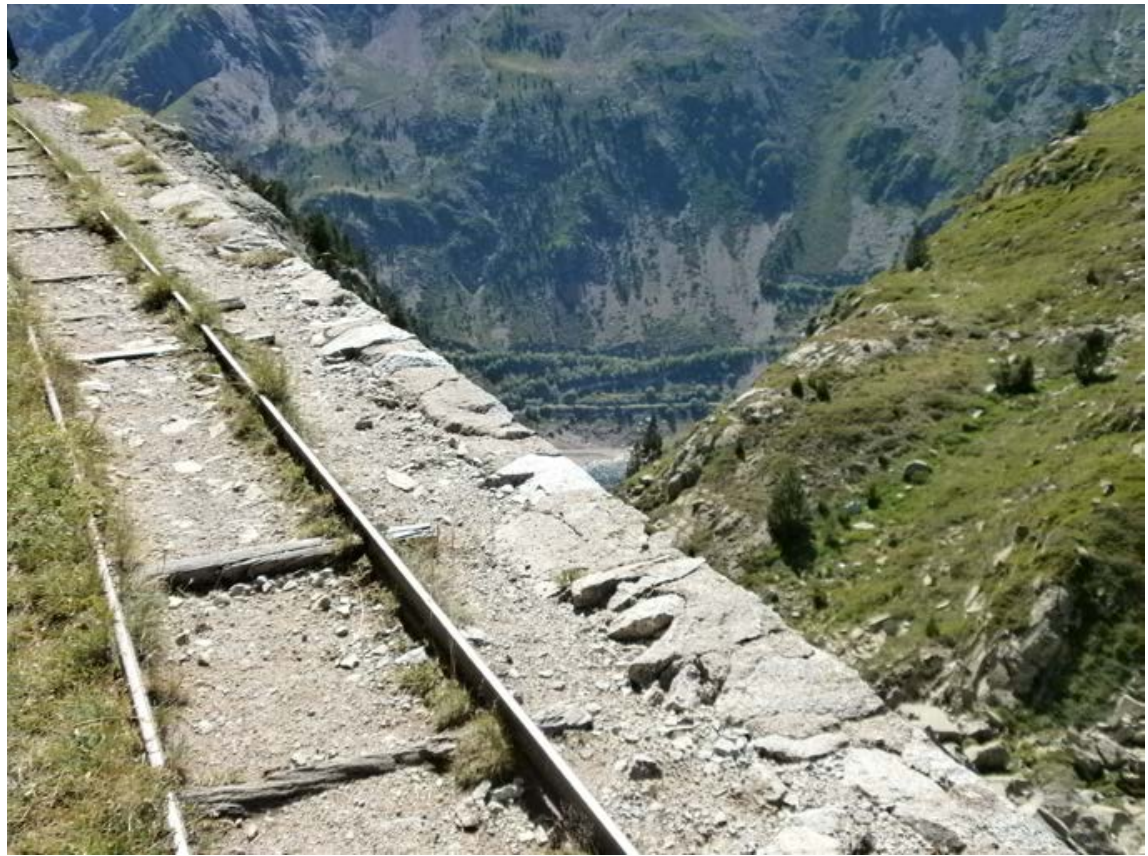

Fotografia 7. Un altre aspecte de la via del ferrocarril. Al fons es veu una petita part de I'Embassament de Sallente. Agost 2013.

\subsection{Parada 6. ESTANY GENTO, (Cabdella, terme municipal de la Torre de Cabdella, comarca del Pallars Jussà). (Full 181).}

Des de la parada anterior, cal continuar pel vial del ferrocarril, anant cap a l'Estany Gento. Així, hi arribarem en un nou recorregut, proper al $1^{\prime} 5 \mathrm{Km}$ des de la parada anterior. D'aquesta forma, haurem completat tot el recorregut d'aquest vial.

Com és evident, aquest recorregut, I'haurem fet. Íntegrament, per la Zona Axial Pirinenca. Així, haurem vist afloraments dels materials paleozoics esmentats a les aturades anteriors. Més amunt, haurem començat a trobar afloraments dels materials granítics (fonamentalment: granits i granodiorites). Aquests materials són els que apareixen pels voltants de I'Estany Gento, on estem ara situats. Així, per arreu es poden veure afloraments d'aquestes roques d'edat carbonífera, relaciones amb el plegament variscic (o hercinià).

L'Estany Gento, constitueix un dels principals llacs dels Pirineus de Catalunya. Te una clara morfologia glacial, formada pel soscavament de les glaceres sobre les roques granítiques acabades d'esmentar. Alhora, forma part de l'important complex lacustre de la Vall Fosca, format per nombrosos llacs, com els propers Estany Mar i Estany Tort, entre molts altres que donen les aigües al Noguera de Flamisell. (fotografia 8).

Precisament, totes les aigües dels llacs anteriors i les d'altres, de tot el complex lacustre de la Vall Fosca, són canalitzades cap l'embassament de Sallente, que hem vist a la parada anterior. Cal dir, que des de el camí d'ascens cap a l'Estany Gento i des del mateix llac, es poden gaudir d'unes interessants vistes de l’Embassament de Sallente. 


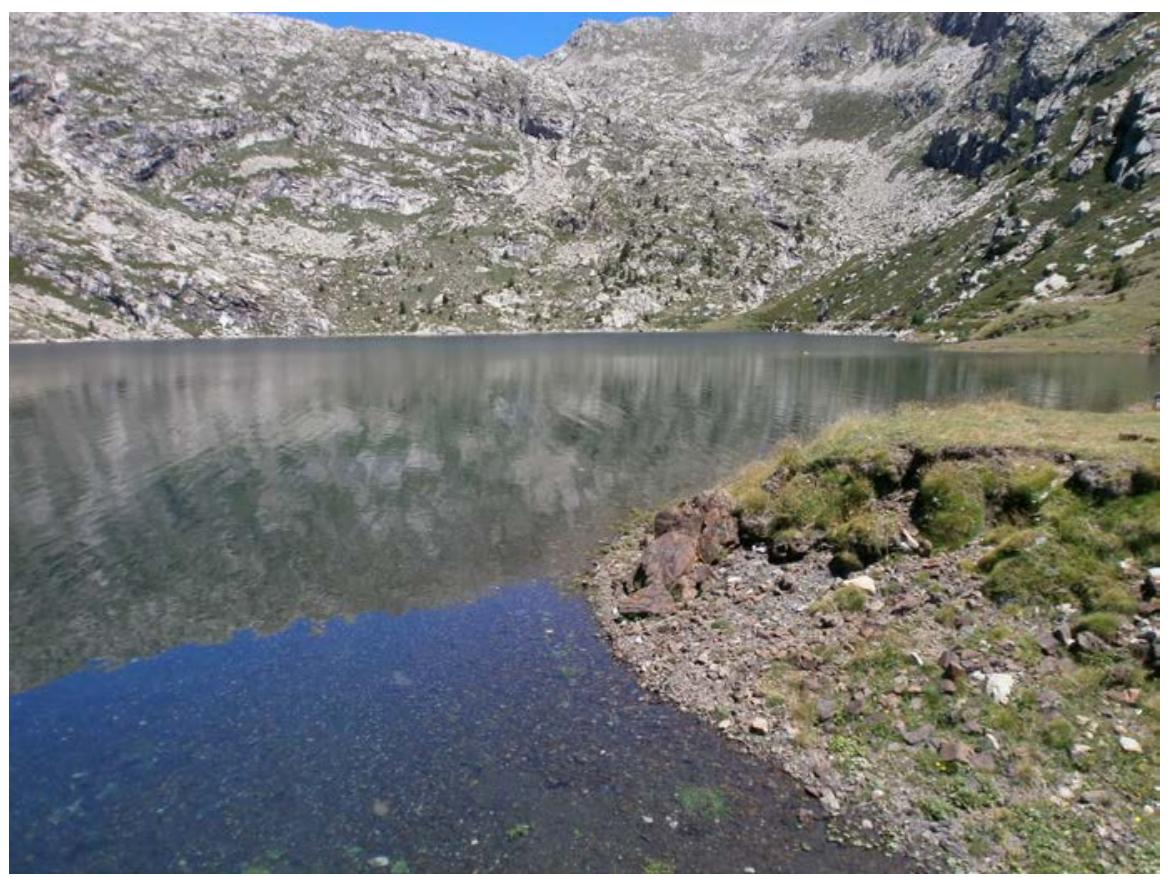

Fotografia 8. L’Estany Gento, entre afloraments de roques granítiques. Agost 2013

Cal dir, que poc abans d'arribar a aquest indret, haurem vist una important esllavissada, prop de la via, entre les granodiorites del Carbonífer. (fotografia 9).

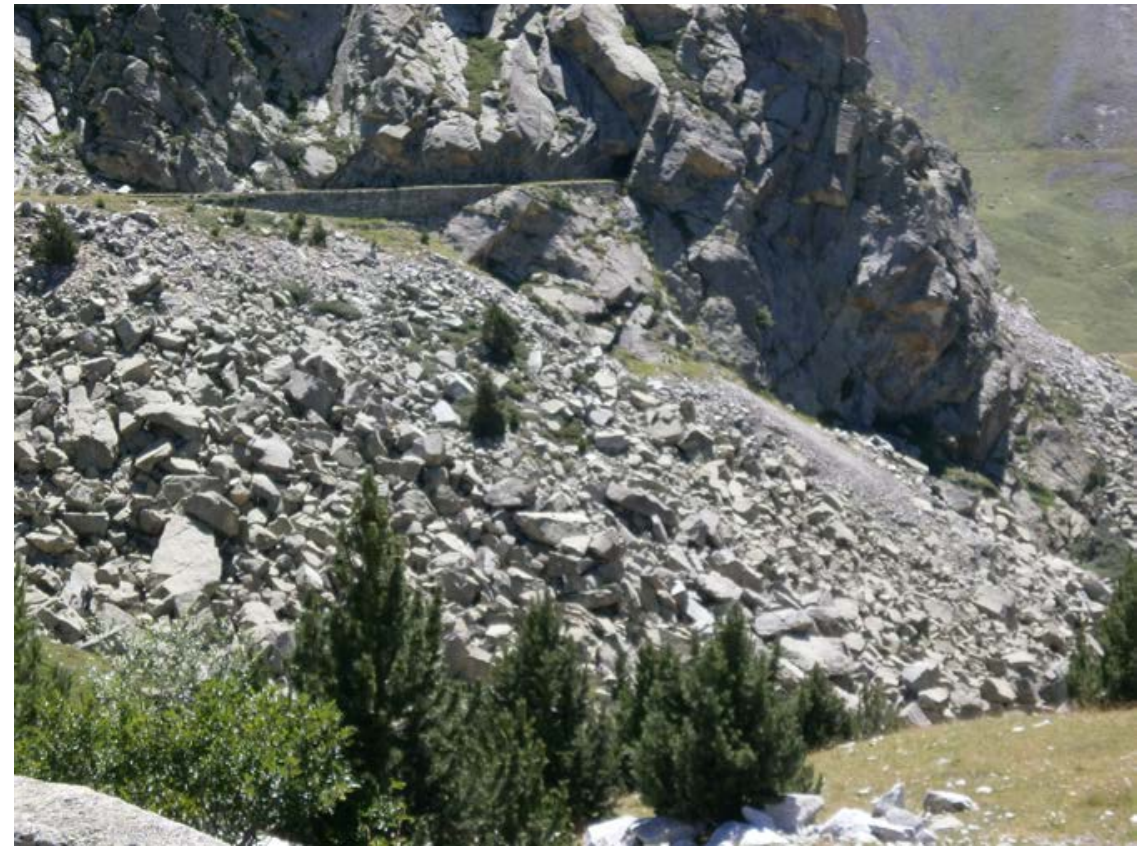

Fotografia 9. Un aspecte de l'esllavissada de les granodiorites, prop de l'Estany Gento Vall Fosca): des d'Espui, al Coll de Triador, I'Estany Gento, I'Estany Tort i a Colomines 
També cal dir, que des del Refugi de l'Estany Gento (situat prop de l'Estació del Telefèric), es pot fer una bona observació de l'Embassament de Sallente, per sobre del qual ens trobem ara situats. (fotografia 10). Aquesta observació, es pot complementar amb la de les (fotografia 11 i 12).

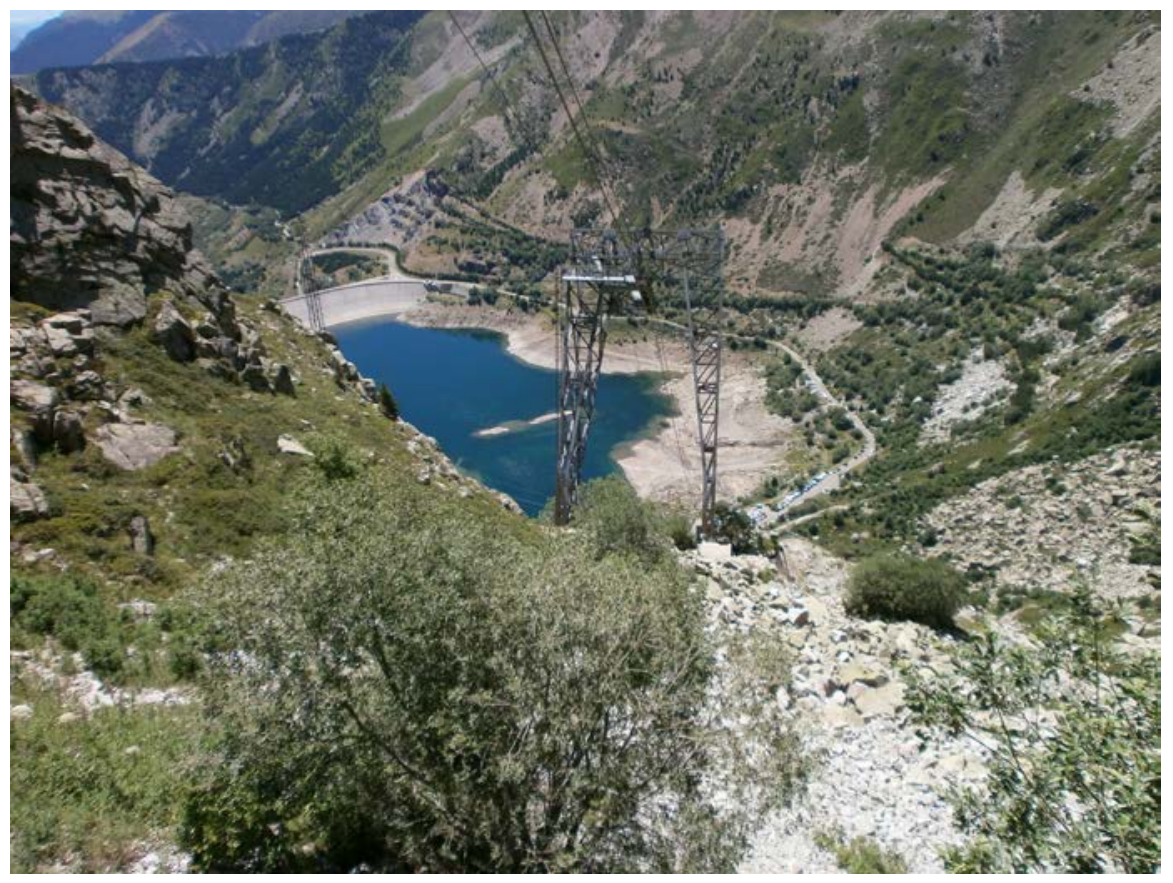

Fotografia 10. L'embassament de Sallente, vist des del Refugi de l'Estany Gento Al fons es veuren les roques grises metamòrfiques de l'Ordovicià i Cambro - Ordovicià Pel centre es fa palesa I'Aureola Metamòrfica I en primer terme es veuen les roques granítiques Agost 2013

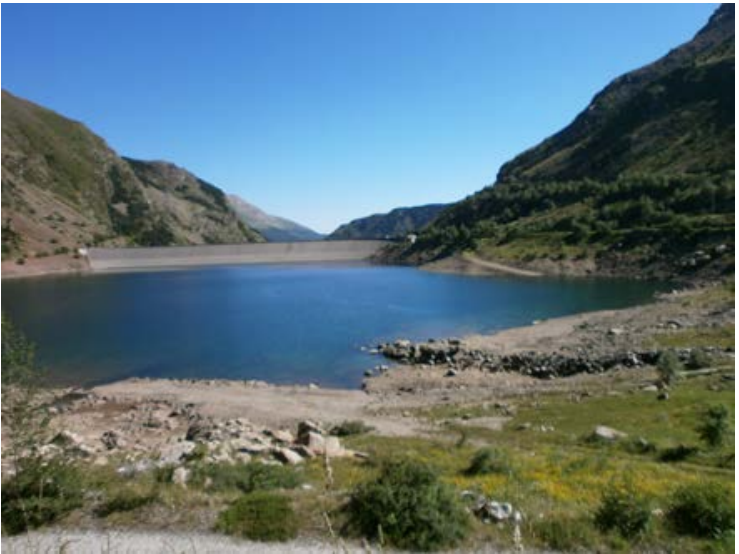

Fotografia 11. Un aspecte de l'embassament de Sallente Juliol 2013

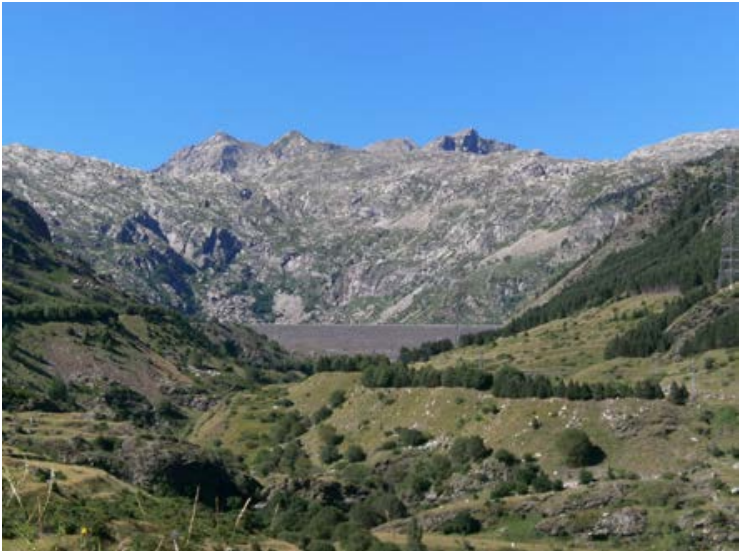

Fotografia 12. Aflorament dels granits, al sector septentrional de Sallente / Juliol 2013 
Pel que fa a aquesta aturada, cal dir que prop del Refugi de I'Estan Gento, apareix un interessant contacte entre les roques granodiorítiques i els materials pissarrencs del Silurià. (fotografia 13).

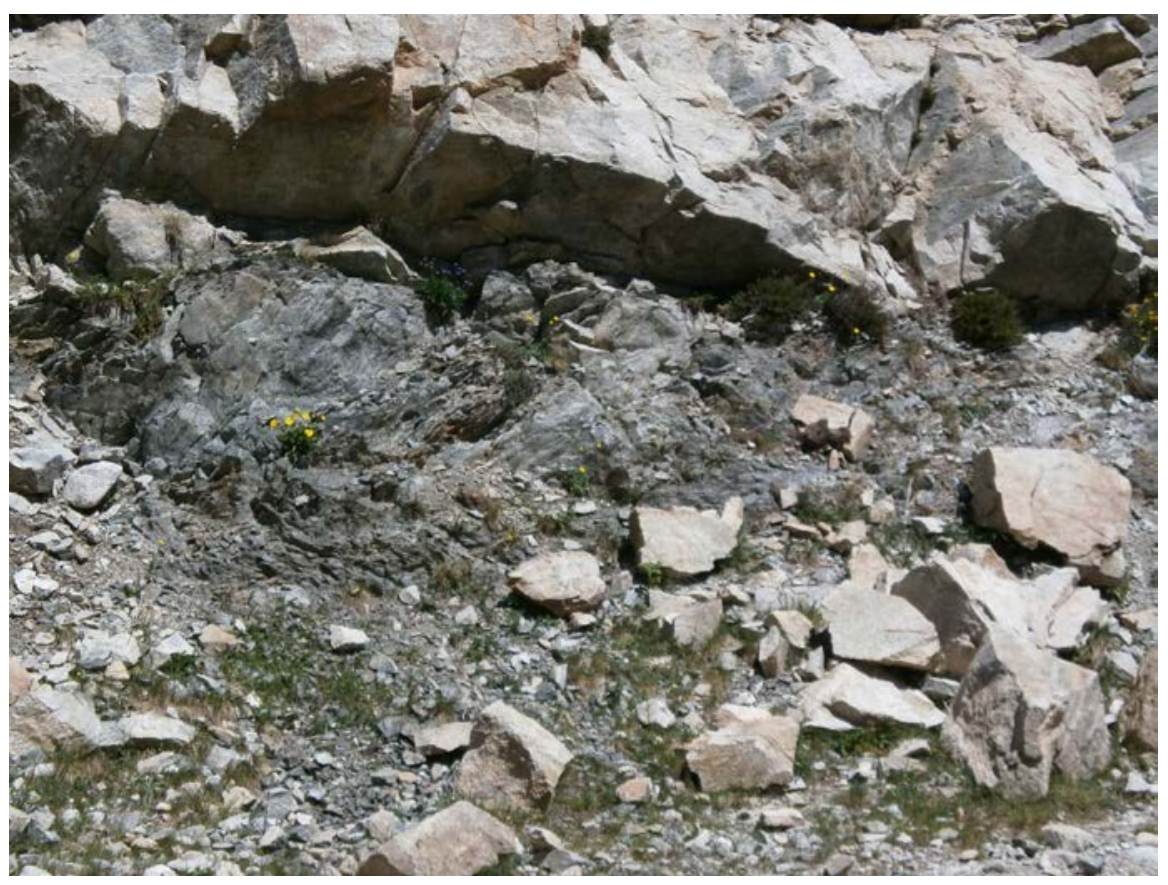

Fotografia 13. Contacte entre les granodiorites i els materials del Silurià. Al Refugi de I'Estany Gento. Agost 2013

I, finalment, mirant cap a llevant, es pot gaudir d'una bona visió del Montorroio, situat al Nord del Montsent de Pallars. (fotografia 14). Vall Fosca): des d’Espui, al Coll de Triador, I'Estany Gento, I'Estany Tort i a Colomines 


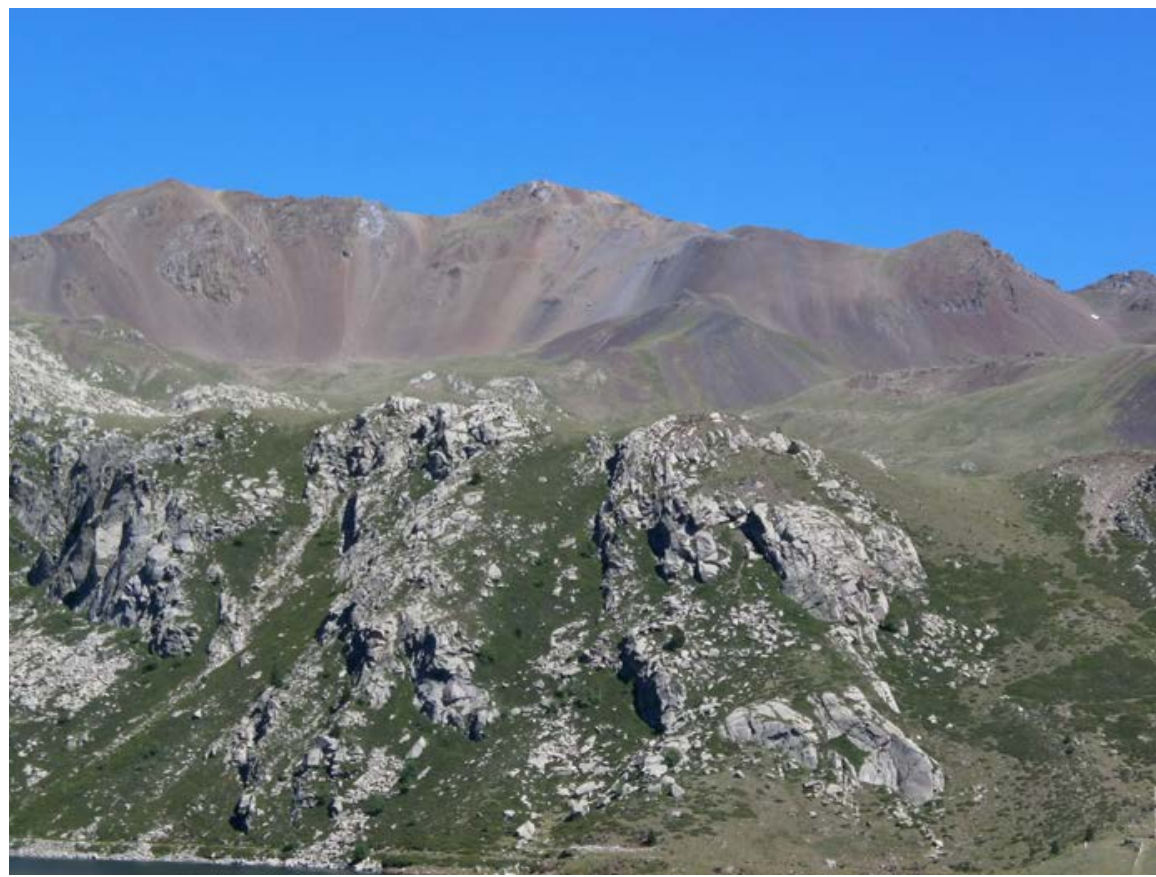

Fotografia 14. El Montorroio Aamb afloraments del Devonià).

En primer terme les granodiorites. Agost 2013

\subsection{Parada 7 - CONDICIONAL. IMMEDIACIONS DEL REFUGI COLOMINA, (Cabdella, terme de la Torre de Cabdella, comarca del Pallars Jussà). (Full 181).}

Després de realitzar l'aturada anterior, si s'escau, pot efectuar-se un nou recorregut a peu, amb la finalitat d'arribar fins al Refugi Colomina, per on farem una nova aturada, després d'un recorregut proper a 1 hora, havent pujat un desnivell proper als 300 metres.

En aquest recorregut, realitzat totalment dintre de la Zona Axial Pirinenca, haurem continuat trobant afloraments de les roques granítiques que ja hem vist en el recorregut cap a l'aturada anterior. Així, en aquest tram, haurem també trobat, fonamentalment, les granodiorites del Carbonífer

Per altra banda, des d'aquest indret, es pot observar per arreu, la interessant morfologia glacial de la zona, com la que es veu a l'Estany Tort. Aquest estany el trobarem abans d'arribar a I'Estany de Colomina situat a tocar del refugi del mateix nom.

En aquest indret finalitza el recorregut de l'itinerari 


\section{Bibliografia}

GUIMERÀ, J. et altri (1992).- Geologia (II), Història Natural dels Països Catalans, Vol. 2, 547 pag. Enciclopèdia Catalana, S.A. Barcelona.

IGME (1994).- Mapa Geológico de España a escala 1:50.000 (Plan Magna). Fulla i Memòria $\mathrm{n}^{\circ}$ 252 (Tremp). Inst. GeoMinero y Tecnol. España. Minist. Indústria. Madrid.

MARTÍNEZ RIUS, A. Et altri (2013).- Guia Geològica del Parc Natural d’Aigüestortes i Estany de Sant Maurici. Publicada a Guies Geològiques dels Parcs Nacionals (dirigida per Roberto Rodríguez Fernández). IGME -Edit Everest. 225 pàgines. Madrid.

MATA-PERELLÓ, J.M. (1991).- Els Minerals de Catalunya. Arxius de la Secció de Ciències de I'Institut d'Estudis Catalans, vol.47, 545 pàgines. Barcelona.

MATA-PERELLÓ, J.M. (2013a).- Recorregut de recerca geològica i mineralògica per la comarca del Pallars Jussà: des de Senterada, a la Pobleta de Bellveí, a la Plana de Mont-ros, a Cabdella i a Sallente. Inèdit. 14 pàgines. Manresa.

MATA-PERELLÓ, J.M. (2013b).- Recorregut de recerca geològica i mineralògica per la comarca del Pallars Jussà: des de la Torre de Cabdella cap a Cabdella, Sallente i cap I'Estany Gento. Inèdit. 12 pàgines. Manresa.

MATA-PERELLÓ, J.M. (2013c).- Recorregut de recerca geològica i mineralògica per la comarca del Pallars Jussà: des d’Espui, cap al Coll de Triador, I'Estany Gento, I'Estany Tort i cap a Colomines, Inèdit. 14 pàgines. Manresa.

MATA-PERELLÓ, J.M. i SANZ BALAGUÉ, J. (1993).- Guía de identificación de Minerales, adaptada fundamentalmente a la Península Ibérica. Parcir, Edic. Selectas, 243 pàgines. Manresa.

RIBA ARDERIU, O. et altri (1976).- Geografia Física dels Països Catalans. Edit Ketres. 211 pàgines. Barcelona.

ROSELL SANUI, J. (1970).- Explicació del Mapa Geològic, a escala 1:50.000, corresponent al full nº 252 (Tremp). Mapa Geológico de España. Inst. Geológico y Minero de España. Madrid. 